\title{
Anti-angiogenic activity of the flavonoid precursor 4-hydroxychalcone
}

\author{
Lenka Varinska ${ }^{\mathrm{a}}$, Michiel van Wijhe ${ }^{\mathrm{b}}$, Mirella Belleri ${ }^{\mathrm{c}}$, Stefania Mitola ${ }^{\mathrm{c}}$, Pal Perjesi ${ }^{\mathrm{d}}$, Marco Presta ${ }^{\mathrm{c}}$, \\ Pieter Koolwijk ${ }^{b}$, Lenka Ivanova ${ }^{a}$, Jan Mojzis ${ }^{\mathrm{a}, *}$ \\ a Department of Pharmacology, Faculty of Medicine, Pavol Jozef Safarik University, Trieda SNP 1, 04011 Kosice, Slovak Republic \\ ${ }^{\mathrm{b}}$ Laboratory for Physiology, Institute for Cardiovascular Research, VU University Medical Center Amsterdam, Amsterdam, The Netherlands \\ ${ }^{\mathrm{c}}$ Department of Biomedical Sciences and Biotechnology, Unit of General Pathology and Immunology, School of Medicine, University of Brescia, Brescia, Italy \\ ${ }^{\mathrm{d}}$ Institute of Pharmaceutical Chemistry, Faculty of Medicine, University of Pecs, Pecs, Hungary
}

\section{A R T I C L E I N F O}

\section{Article history:}

Received 20 December 2011

Received in revised form

23 April 2012

Accepted 10 June 2012

Available online 18 June 2012

\section{Keywords:}

Angiogenesis

Chalcones

Endothelial cells

In vitro

CAM assay

\begin{abstract}
A B S T R A C T
Angiogenesis, the growth of new blood vessels, is necessary for cancerous tumors to keep growing and spreading. Suppression of abnormal angiogenesis may provide therapeutic strategies for the treatment of angiogenesis-dependent disorders. In the present study, we describe the in vitro and in vivo antiangiogenic activities of the flavonoid precursor 4-hydroxychalcone (Q797). This chalcone $(22 \mu \mathrm{g} / \mathrm{ml})$ suppressed several steps of angiogenesis, including endothelial cell proliferation, migration and tube formation without showing any signs of cytotoxicity. Moreover, we found a selective effect on activated endothelial cells, in particular with resting endothelial cells and the human epithelial tumor cell lines (HeLa, MCF-7, A549). In addition, Q797 was able to modulate both vascular endothelial growth factor (VEGF)- and basic fibroblast growth factor (FGF)- induced phosphorylation of extracellular signalregulated kinase (ERK)-1/-2 and Akt kinase. It did not influence the nuclear translocation of p65 subunit of the nuclear factor- $\kappa \mathrm{B}(\mathrm{NF}-\kappa \mathrm{B})$ when human endothelial cells were stimulated with tumor necrosis factor (TNF)- $\alpha$. Taken together this indicates that the Q797-mediated inhibition of in vitro angiogenic features of endothelial cells is most likely caused by suppression of growth factor pathways. The potent inhibitory effect of Q797 on bFGF-driven neovascularization was also demonstrated in vivo using the chick chorioallantoic membrane (CAM) assay. In summary, this chalcone could serve as a new leading structure in the discovery of new potent synthetic angiogenesis inhibitors.
\end{abstract}

(c) 2012 Elsevier B.V. All rights reserved.

\section{Introduction}

Angiogenesis is the outgrowth of new blood vessels from pre-existing vasculature. It is a necessary process in embryogenesis and wound healing but also plays a major role in several pathologic processes such as tumor vascularisation, diabetic retinopathy, psoriasis and rheumatoid arthritis (Folkman 1995, 2007). Therefore, newly designed anti-angiogenic agents have potential for the treatment of a broad spectrum of diseases, including cancer (Ribatti, 2009).

An increasing interest is devoted to naturally occurring cancer chemo-preventive agents, including flavonoids, which are rich in fruits, soybeans, vegetables, herbs, roots and leaves (Hollman and Katan, 1999; Larsen et al., 2010; Yang et al., 2011). These polyphenolic compounds display a remarkable spectrum of biological

\footnotetext{
* Corresponding author. Tel./fax: + 421556428524.

E-mail addresses: lenka.varinska@upjs.sk (L. Varinska), m.vanwijhe@vumc.nl (M. van Wijhe), mbelleri@med.unibs.it (M. Belleri), mitola@med.unibs.it (S. Mitola), pal.perjesi@aok.pte.hu (P. Perjesi), presta@med.unibs.it (M. Presta), p.koolwijk@vumc.nl (P. Koolwijk), lenka.ivanova@student.upjs.sk (L. Ivanova), jan.mojzis@upjs.sk (J. Mojzis).
}

activities including those that might be able to influence processes that are dysregulated during cancer development. They selectively induce apoptosis in various human carcinoma cell lines and they are thought to be involved in the suppression of angiogenesis (Lamoral-Theys et al., 2010).

Many fruits and vegetables are also rich dietary sources of flavonoid precursors, in particular the chalcones. These compounds could make a great contribution to the total daily intake of natural polyphenolics (Tomas-Barberan and Clifford, 2010), since they appear to possess potentially beneficial effects against various diseases (de Campos-Buzzi et al., 2006; Sharma et al., 2009). Indeed, they are associated with several biologically active properties, including anti-inflammatory (Hsieh et al., 2000; Won et al., 2005), anti-oxidative (Nerya et al., 2004), anti-fungal (Sivakumar et al., 2009a), anti-bacterial (Sivakumar et al., 2009b), chemo-preventive and anti-cancer activities (Ducki, 2007; Chua et al., 2010; Katsori and Hadjipavlou-Litina, 2009; Liu and Go, 2006; Modzelewska et al., 2006). Although there are an increasing number of articles relating the anti-cancer activities of chalcones, limited information is available about a possible anti-angiogenic activity of this class of compounds (Kang et al., 2010; Kim et al., 2010; Mojzis et al., 2008). 
The structural features of chalcones presence of a reactive enone moiety and its relative flexibility compared to other related natural products predispose the template to interactions with diverse receptors and enzymes (Go et al., 2005), as well as their biological properties prompted us to investigate whether chalcones and newly synthesized cyclic chalcone analogues modulate angiogenesis in both in vitro and in vivo models. We present for the first time the evidence that one of the chalcones; 4-hydroxychalcone (Q797) inhibits different steps of the angiogenesis process in vitro by affecting both vascular endothelial growth factor (VEGF) and basic fibroblast growth factor (bFGF) intracellular signaling. In line with this in vitro data, Q797 also caused a significant anti-angiogenic activity in vivo. Q797 may represent the basis for the design of novel anti-angiogenic chalcone derivatives.

\section{Materials and methods}

\subsection{Chemicals}

Medium 199 with 20 mM HEPES (M199), penicillin, streptomycin and newborn calf serum (NBCS) were obtained from Lonza (Verviers, Belgium). Tissue plastics were from Corning Life Science (Lowell, MA USA) and L-glutamine from Sigma-Aldrich (St. Louis, MO USA). Human serum (HS) was obtained from PAA (Pasching, Austria). Basic fibroblast growth factor (bFGF) was purchased from Sigma-Aldrich (St. Louis, MO USA), vascular endothelial growth factor (VEGF-A) from Biosource (Camarillo, CA USA) and tumor necrosis growth factor (TNF) $\alpha$ was obtained from R\&D Systems (Minneapolis, MN USA). Matrigel basement membrane matrix was obtained from Becton Dickinson Labware (Bedford, MA USA). The chalcones: 4-hydroxychalcone (Q797), 4-methylchalcone (Q171), 4-methoxychalcone (Q126), 4-dimethylaminochalcone (Q192) and the cyclic chalcone analogues: (E)-2-(X-benzylidene)-1-indanones ((E)-2-(4-dimethylaminobenzylidene)-1-indanone (Q560), (E)-2-(4-methoxybenzylidene)-1-indanone (Q397), (E)-2-(4-hydroxybenzylidene)-1-indan one (Q764)), (E)-2-(2,4-dimethoxybenzylidene)-1-tetralone (Q705), (E)-2-(X-benzylidene)-1-benzosuberones ((E)-2-(4-methoxybenzylidene)-1-benzosuberone (Q510), (E)-2-(4-hydroxybenzylidene)-1benzosuberone (Q766)) were synthesized as described below by $\mathrm{dr}$. Perjesi (University Medical School of Pecs, Hungary).

Other materials used in the methods described below have been specified in detail in related references or in the text or were purchased from standard commercial sources.

\subsubsection{Synthesis of non-hydroxyl substituted chalcones}

A methanol solution of sodium hydroxide $(0.005 \mathrm{M})$ was added to methanol solutions of equimolar $(0.01 \mathrm{M})$ amounts of acetophenone, cyclic ketone or aromatic aldehyde. The mixture was allowed to incubate at room temperature for two days, and precipitated at $4{ }^{\circ} \mathrm{C}$. The dried precipitate was subjected to the column chromatography over Kieselgel 60 (Merck, Ralway, NJ USA) and the pure chalcone was crystallized from methanol. The purity of the compounds was checked by TLC using Merck silica gel 60 F254 alumina sheets. The structure and stereochemistry of the compounds was characterized by elemental analysis, IR and NMR methods (Dimmock et al., 1999; Perjesi et al., 1999).

\subsubsection{Synthesis of hydroxyl substituted chalcones}

A few drops of piperidine were added to an equimolar $(0.01 \mathrm{M})$ amount of acetophenone, cyclic ketone or aromatic aldehyde and the mixture was heated at $120^{\circ} \mathrm{C}$ for $1 \mathrm{~h}$. The methanol mixture was then precipitated at $4{ }^{\circ} \mathrm{C}$. The dried precipitate was subjected to column chromatography over Kieselgel 60 (Merck, Ralway, NJ USA), and the pure chalcone was crystallized from hexane (Q797) or methanol (Q764 and Q766). The purity of the compounds was checked by TLC using Merck silicagel 60 F254 alumina sheets. The structure and stereochemistry of the compounds were characterized by elemental analysis, IR and NMR methods. The synthesized Q797 and 4-hydroxyindanone had melting points in accord with the literature values (Dimmock et al., 1998).

\subsection{Cell culture}

Human foreskin microvascular endothelial cells (hMVEC) and human umbilical vein endothelial cells (HUVEC) were isolated, cultured, and characterized as previously described (Defilippi et al., 1991; van Hinsbergh et al., 1987). Cells were cultured on gelatine-coated dishes in cM199 (=M199 medium supplemented with $10 \%$ heat-inactivated human serum, $10 \%$ heat-inactivated new born calf serum, $3.75 \mu \mathrm{g} / \mathrm{ml}$ crude endothelial cell growth factor (ECGF), $5 \mathrm{U} / \mathrm{ml}$ heparin, $100 \mathrm{IU} / \mathrm{ml}$ penicillin, and $100 \mu \mathrm{g} / \mathrm{ml}$ streptomycin) at $37{ }^{\circ} \mathrm{C}$ under $5 \% \mathrm{CO}_{2} / 95 \%$ air atmosphere.

Twenty-four hours prior to experiments endothelial cell cultures were refreshed with medium without crude endothelial cell growth factor and heparin.

The human cervical adenocarcinoma cell line HeLa was cultured in RPMI-1640 medium (PAA Laboratories, Pasching, Austria) supplemented with $10 \%$ fetal bovine serum and antibiotics (penicillin $100 \mathrm{U} / \mathrm{ml}$ and streptomycin $100 \mu \mathrm{g} / \mathrm{ml}$; Invitrogen, Carlsbad, CA USA). Human breast adenocarcinoma cell line MCF7 and human lung adenocarcinoma epithelial cell line A549 were cultured in D-MEM medium (Invitrogen, Carlsbad, CA USA) supplemented with $10 \%$ fetal bovine serum and antibiotics (penicillin $100 \mathrm{U} / \mathrm{ml}$ and streptomycin $100 \mu \mathrm{g} / \mathrm{ml}$ ).

\subsection{Formation of capillary like tubular structure in a 3-dimensional matrix}

Human fibrin matrices were prepared in the wells of 96-wells plates by addition of a $100 \mu \mathrm{l}$ solution of a mixture of $0.1 \mathrm{U} / \mathrm{ml}$ thrombin and $2 \mathrm{mg} / \mathrm{ml}$ plasma-derived, plasminogen-depleted fibrinogen (Calbiochem, La Jolla, CA USA) in M199 medium as described previously (Koolwijk et al., 1996). After preparation of the matrices, confluent endothelial cell monolayers $\left(0.7 \times 10^{5}\right.$ cells $/ \mathrm{cm}^{2}$ ) were detached, concentrated and seeded in a $1.25: 1$ split ratio on the fibrin matrices and cultured for $24 \mathrm{~h}$ in M199 supplemented with $10 \%$ HS, 10\% NBCS, and penicillin/streptomycin before stimulating the cells with serum-containing M199 with or without (control) $10 \mathrm{ng} / \mathrm{ml} \mathrm{bFGF}$ or $25 \mathrm{ng} / \mathrm{ml} \mathrm{VEGF,} \mathrm{and} 10 \mathrm{ng} / \mathrm{ml}$ TNF- $\alpha$. Every second or third day, the culture medium was collected and fresh medium was added. Invading cells and the formation of tubular structures of endothelial cells in the 3-D fibrin matrix were analyzed by phase contrast microscopy. The total length of tube-like structures of 4 randomly chosen microscopic fields in triplicate wells was measured using a Nikon FXA microscope equipped with a monochrome CCD camera (MX5) connected to a computer with Optimas image analysis software and expressed as $\mathrm{mm} / \mathrm{cm}^{2}$.

\subsection{In vitro Matrigel angiogenesis assay}

The effect of Q797 on the ability of HUVEC to reorganize and differentiate into capillary-like networks was assessed in the in vitro Matrigel morphogenesis assay as described previously (Grant et al., 1989). Matrigel $(9.8 \mathrm{mg} / \mathrm{ml})$ was thawed at $4{ }^{\circ} \mathrm{C}$, and $50 \mu \mathrm{l}$ was quickly added to wells of a 96-well plate and allowed to solidify for $30 \mathrm{~min}$ at $37^{\circ} \mathrm{C}$. HUVEC were seeded at a cell density of 15,000 cells/well. Medium supplemented with VEGF $(25 \mathrm{ng} / \mathrm{ml})$ and different concentrations of studied compounds $(0.22,2.2,22 \mu \mathrm{g} / \mathrm{ml}$ ) was added for $8 \mathrm{~h}$. The formation of capillary-like structures was examined microscopically and photographs were taken using a 
camera (Leica Microsystems, Wetzlar, Germany) and Leica DM IL microscope (Leica Microsystems, Wetzlar, Germany).

\subsection{Assessment of monolayer integrity and cell viability}

Endothelial cells were seeded and grown to confluence in 24wells plates and then treated with serial dilutions of Q797 in cM199 medium. Pictures of the monolayers were taken using a camera at the time points 24, 72 and 144 h (Leica Microsystems, Wetzlar, Germany) and the number of cells were counted. In parallel, cell viability at $24 \mathrm{~h}$ was determined by Trypan blue exclusion test.

\subsection{Two dimensional migration (wound healing) assay}

The motility of HUVEC was assayed using a wound healing assay (Martínez-Poveda et al., 2005). Briefly, endothelial cells were cultured on the 24-well plate in the cM199 medium until confluent. A $2 \mathrm{~mm}$ tip of a pipette was used to wound the monolayer of cells. Afterwards, the medium was replaced with fresh ECGF and heparin-free medium containing the studied compounds at different concentrations in the presence of $25 \mathrm{ng} / \mathrm{ml}$ of recombinant VEGF. The wounded area was photographed at the start $(t=0 \mathrm{~h}$ ) and at time point $t=15 \mathrm{~h}$. The migration distance (gap size) was determined using image analysis software. The experiments were performed in duplicate wells and repeated three times with cells from different donors.

\subsection{Methyl-thiazole-tetrazolium (MTT) assay}

The assay conditions were essentially the same as described previously (Kaspers et al., 1994). Briefly, aliquots of $80 \mu \mathrm{l}$ cell suspension ( 4000 cells/well) were added to 96-well microculture plates. Twenty-four hours after seeding, $20 \mu \mathrm{l}$ aliquots of drug solutions $(0.22 ; 2.2 ; 22 \mu \mathrm{g} / \mathrm{ml})$ were added to the HUVEC in triplicate wells for $6 \mathrm{~h}$. Cultures were then washed and allowed to grow for the next $42 \mathrm{~h}$. Alternatively cultures were incubated with the compound for $48 \mathrm{~h}$ throughout the whole experimental period. The tumor cell lines (HeLa, MCF-7, A549) were cultured in the presence or absence of different concentrations of Q797 for $72 \mathrm{~h}$. After $72 \mathrm{~h}$ of culturing, $10 \mu \mathrm{l}$ of the MTT solution (SigmaAldrich, St. Louis MO USA) was added to each well and incubated for another $4 \mathrm{~h}$. Then, the formazan crystals were dissolved with $100 \mu \mathrm{l}$ of $10 \%$ SDS. The optical density (OD) was measured at $540 \mathrm{~nm}$ with an EL-312 microplate reader (Biotek Instruments Inc., Winooski, VT USA), and cell survival was calculated.

\subsection{Western blot analysis}

Cell lysates for phospho-Akt and phospho-ERK detection were prepared as follows: equal numbers of HUVEC cultured on gelatincoated wells, were washed with ice-cold PBS and lysed using a lysis buffer containing: $0.02 \mathrm{M}$ Tris $/ \mathrm{HCl}(\mathrm{pH}=8), 0.15 \mathrm{M} \mathrm{NaCl}, 0.09 \mathrm{M} \mathrm{KCl}$, $2 \mathrm{mM}$ EDTA/NaOH, 5\% Igepal (Sigma-Aldrich, St. Louis, MO USA), $0.5 \%$ Triton-X-100, $1 \mathrm{mM} \mathrm{Na} \mathrm{VO}_{4}, 0.05 \mathrm{M} \mathrm{NaF}$, protease inhibitor cocktail (Sigma-Aldrich, St. Louis, MO USA) and phosphatase inhibitor cocktail. The lysates were clarified by centrifugation at $14,000 \mathrm{rpm}$ during $15 \mathrm{~min}$. at $4{ }^{\circ} \mathrm{C}$. Protein concentration was measured using Bio-Rad $\mathrm{D}_{\mathrm{c}}$ Protein Assay (Bio-Rad, Hercules, CA USA). Equal amount $(20 \mu \mathrm{g})$ of protein samples were separated on a $12 \%$ SDS-polyacrylamide gel and electrophoretically transferred $(100 \mathrm{~V}$, $2 \mathrm{~h}$ ) onto a nitrocellulose membrane (Pall Gelman Laboratory, Ann Arbor, MI USA). Afterwards the membranes were blocked for $1 \mathrm{~h}$ using $5 \%$ non-fat dry milk. The following primary antibodies were used: anti-phospho-ERK1/2 (Cell Signaling Technology, Beverly, MA USA, 1:2000) or anti-phospho-Akt (Cell Signaling Technology, Beverly, MA USA, 1:2000). The membranes were incubated with the indicated antibodies in $1 \%$ non-fat milk at $4{ }^{\circ} \mathrm{C}$ for $18 \mathrm{~h}$. After four times washing with $0.2 \%$ PBS-Tween 20 , goat-anti-rabbit-HRP (Santa-Cruz Biotechnology, Santa Cruz, CA USA, sc-2004, 1:2000) or goat-anti-mouse-HRP (Dako, Carpinteria, CA USA, p0447, 1:2000) antibodies were added and membranes were incubated for $2 \mathrm{~h}$ at room temperature. Membranes were washed in 0.2\% PBS-Tween 20

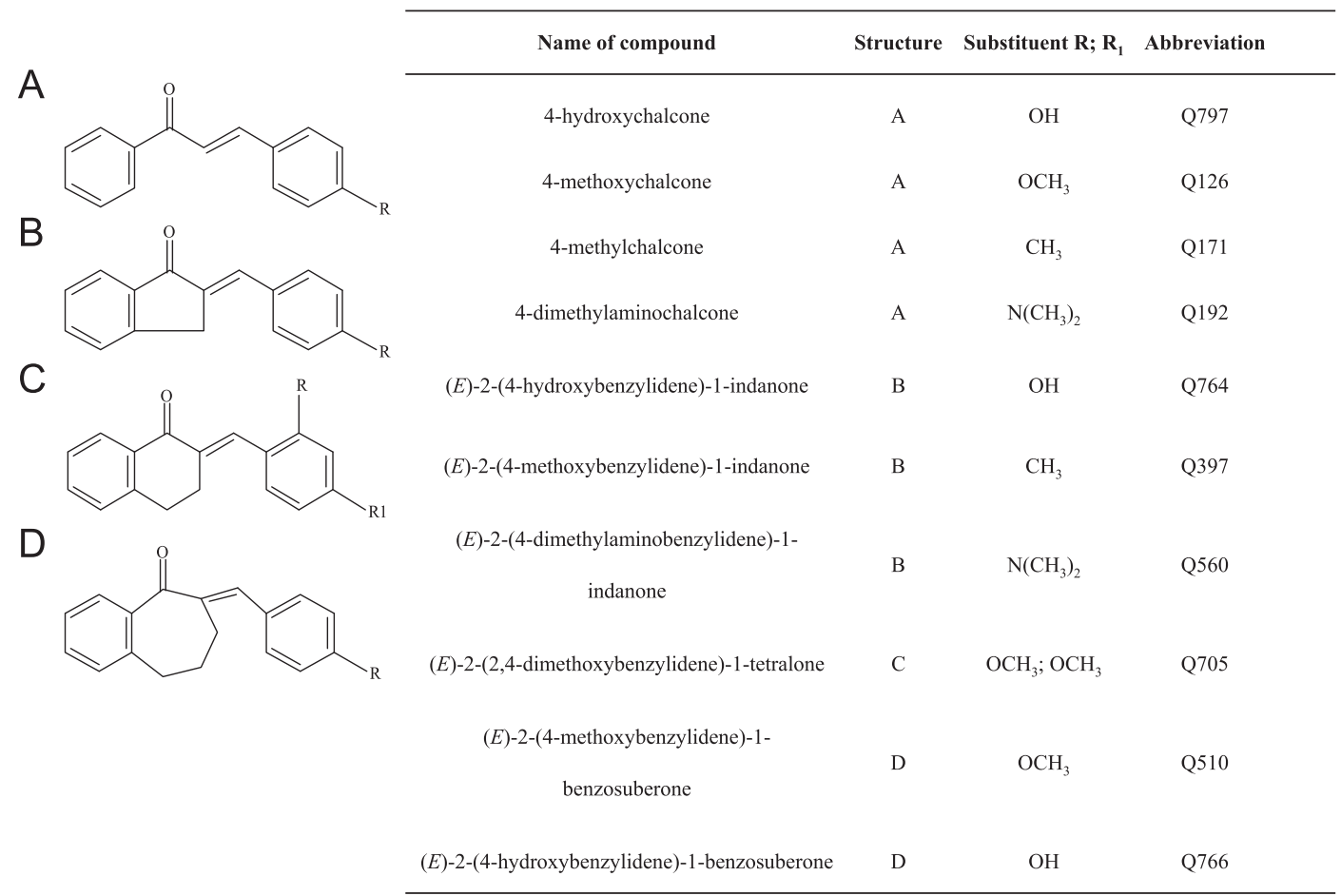

Fig. 1. Chemical structures of chalcones and cyclic chalcone analogues used in this study. 
and proteins were visualized by enhanced chemiluminescence (Pierce, Rockford, IL USA) according to manufacturer's instructions on X-ray film (Pierce, Rockford, IL USA). Signal intensity of p-ERK and p-Akt was determined densitometrically (software Quantity One, Bio-Rad) and expressed relative to total ERK or Akt.

\section{9. $N F-\kappa B$ (p65 subunit) immunofluorescence staining}

HUVEC were cultured to confluence on gelatin-coated glass cover-slips (14 mm diameter). After washing, the cells were preincubated in medium supplemented with $10 \%$ HS and 10\% NBCS with or without $22 \mu \mathrm{g} / \mathrm{ml}$ Q797. After $1 \mathrm{~h}$, the cells were washed once and stimulated with or without TNF- $\alpha(10 \mathrm{ng} / \mathrm{ml})$, in the presence or absence of Q797 for $1 \mathrm{~h}$. After the incubation, the cells were fixed with $2 \%$ paraformaldehyde, permeabilized using $0.05 \%$ Triton X-100 in PBS for 1 min at a room temperature, washed with PBS, and then incubated with anti-NF- $\kappa B$ antibody (SC 8008FITC, Santa Cruz, 1:250) for $1 \mathrm{~h}$. The cells were then washed and mounted in Slowfade ProLong Gold antifade reagent with DAPI
(Invitrogen, Carlsbad, CA USA). The mean immunofluorescence intensity (MFI) of the nuclei was determined using the image analysis program SlideBook ${ }^{\mathrm{TM}}$ software (version 4.0.8.1; Intelligent Imaging Innovations, Denver, CO, USA). The MFI of 100 nuclei was determined by generating a mask using the DAPI staining and was expressed as arbitrary (fluorescent) units (AU).

\subsection{Chicken embryo chorioallantoic membrane (CAM) assay}

Alginate beads $(5 \mu \mathrm{l})$ containing the sample under test were placed on top of the CAM of fertilized White Leghorn chicken eggs at day 10 of incubation (Knoll et al., 1999). After $72 \mathrm{~h}$, blood microvessels entering the implants within the focal plane of the CAM were counted in ovo at $\mathrm{x} 5$ magnification using a STEMI SR stereomicroscope equipped with an objective f equal to $100 \mathrm{~mm}$ with adapter ring 475070 (Zeiss). The experiments were repeated at least twice with 7-10 eggs per group.
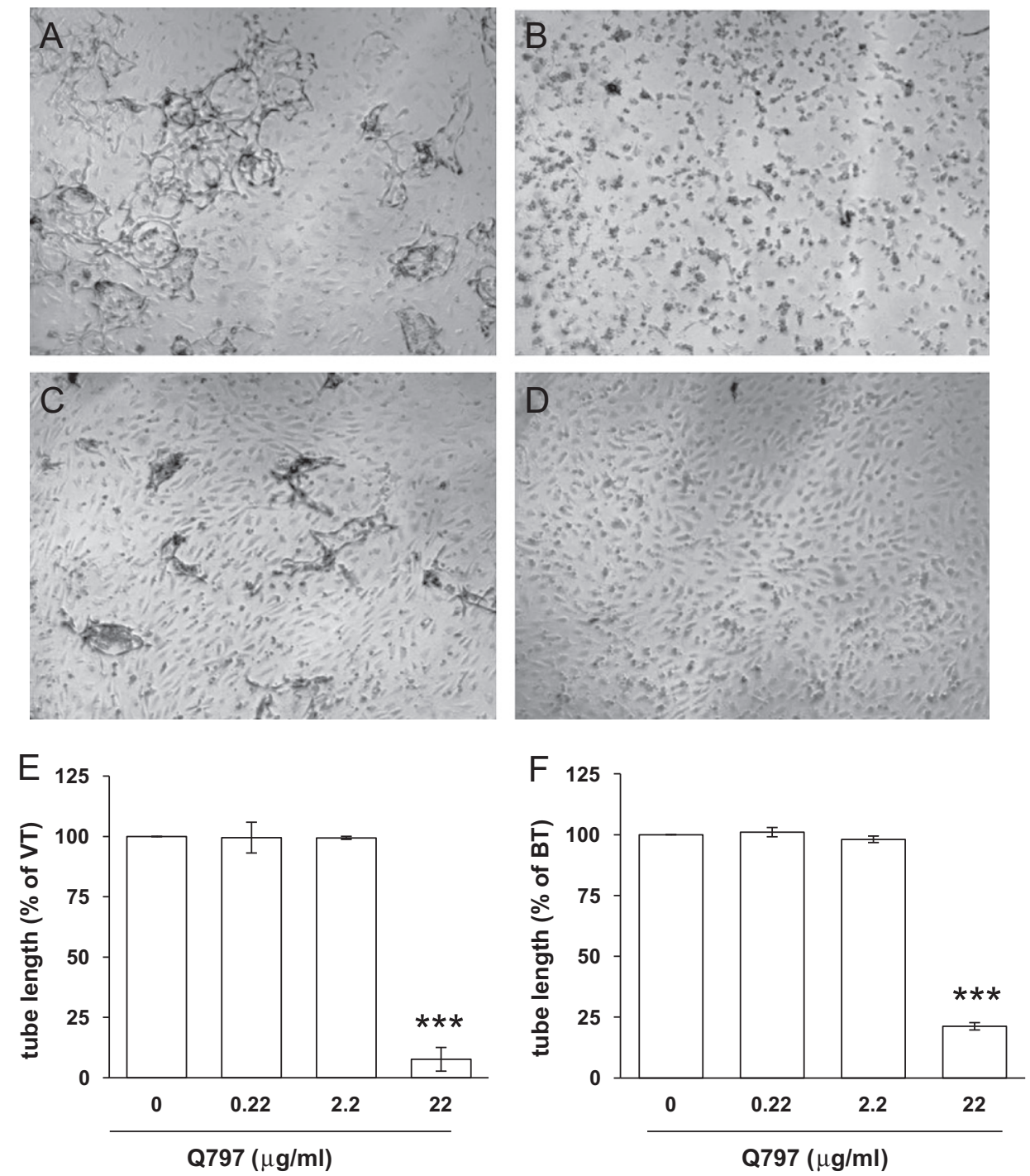

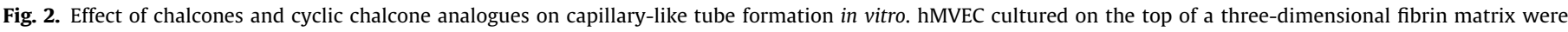

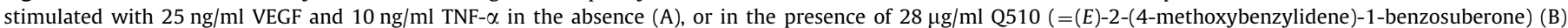

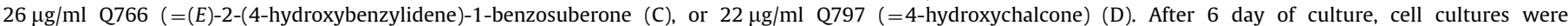

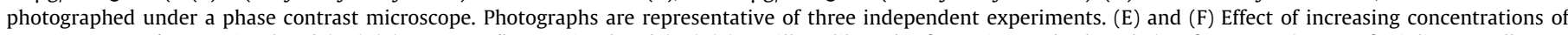

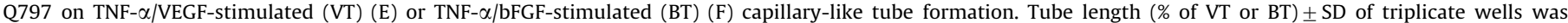
quantified. Similar results were obtained in three independent experiments $(* * *=P<0.001)$. 


\subsection{Statistical analysis}

Results are expressed as mean \pm S.D. Statistical analyses of the data were performed by standard procedures, using a one-way ANOVA followed by Bonferroni Multiple Comparisons Test. Differences were considered significant when $P$ values were smaller than 0.05 .

\section{Results}

3.1. Effect of chalcones and cyclic chalcone analogues on tube formation in 3-D fibrin matrices

A series of 10 chalcones or cyclic chalcone analogues were synthesized differing in their backbone structure and/or chemical substitutions at positions 2 or 4 (see Fig. 1 ).

The compounds were screened for their potential anti-angiogenic activity using an in vitro tube/angiogenesis model (Koolwijk et al., 1996). In this model, hMVEC invade a three-dimensional human fibrin matrix and form capillary-like tubular structures when stimulated with TNF- $\alpha$ in the presence of either VEGF or bFGF (Fig. 2A). Addition of the various chalcones and cyclic chalcone analogues to the cell culture medium resulted in three different biological responses: the compounds Q126, Q171, Q192, Q510 and Q705 exerted a potent cytotoxic effect on the endothelial cell monolayer (see effect of Q510, Fig. 2B). Lowering the concentrations of these compounds reduced not only their cytotoxic activity but also their inhibitory capacity on endothelial tube formation. Compounds Q764 and Q766 exerted a limited effect on endothelial tube formation in the absence of cytotoxicity (Fig. 2C, Q766). Finally, the compounds Q397, Q560, and Q797 induced a significant inhibition in the formation of endothelial tubular structures invading the matrix without any sign of cytotoxicity towards the endothelial cells in the monolayer (Fig. 2D, Q797).

Among the tested compounds, the 4-hydroxychalcone Q797 was shown to be the most effective anti-angiogenic compound and on the basis of that result, the inhibitory activity of Q797 was further characterized. This chalcone significantly suppressed both VEGF/TNF- $\alpha$ - (Fig. 2E) and bFGF/TNF- $\alpha$-induced (Fig. 2F) endothelial tube formation when tested at the concentration of $22 \mu \mathrm{g} / \mathrm{ml}$ $(P<0.001)$, with no significant effect at lower concentrations. For both stimuli, the inhibition occurred in the absence of any cell death or change in morphology of the endothelial cell monolayer adherent to the top of the fibrin matrix (see Fig. 2D).

The lack of cytotoxic activity of Q797 was confirmed when the compound was added to confluent HUVEC (Fig. 3) and hMVEC monolayers (data not shown) cultured in gelatin-coated wells. Also in these experiments, no significant decrease in cell number or increase in cell death, as assessed by trypan blue exclusion staining, was observed when cells were incubated for up to $72 \mathrm{~h}$ with $22 \mu \mathrm{g} / \mathrm{ml} \mathrm{Q797} \mathrm{(data} \mathrm{not} \mathrm{shown).}$

\subsection{Q797 inhibits endothelial cell migration, proliferation and morphogenesis}

To further assess the anti-angiogenic activity of the chalcone analogue, Q797 was tested for its capacity to (i) inhibit cell migration of a mechanically wounded endothelial cell monolayer and (ii) to affect endothelial cell morphogenesis in the Matrigel assay. As shown in Fig. 4A and B, Q797 $(22 \mu \mathrm{g} / \mathrm{ml})$ significantly inhibited migration of VEGF-stimulated HUVEC $(P<0.001)$. No effect was observed at lower concentrations.

Q797 was also tested for its capacity to affect endothelial cell proliferation. After $48 \mathrm{~h}$ of treatment, Q797 $(22 \mu \mathrm{g} / \mathrm{ml})$ significantly
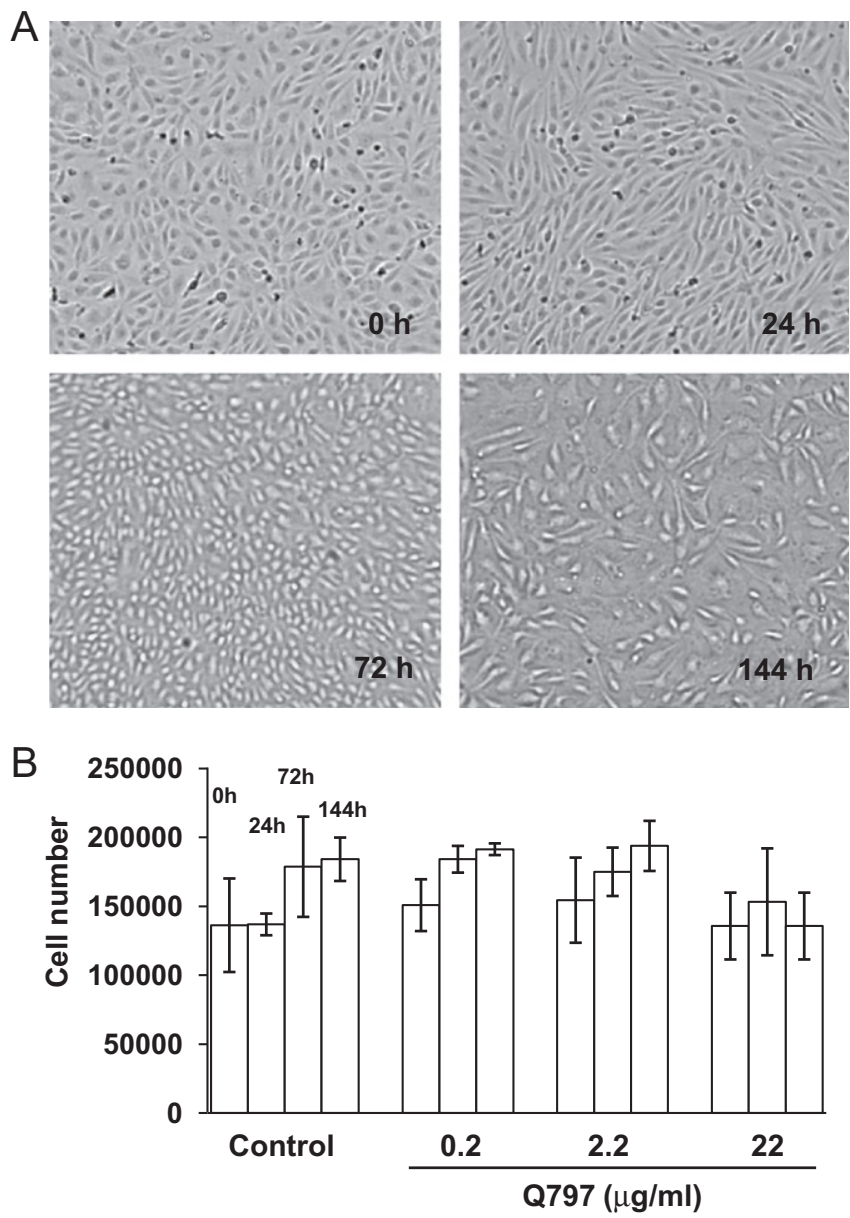

Fig. 3. Influence of Q797 on the monolayer of endothelial cells. HUVEC were cultured in CM199 medium in the presence or absence of various concentrations $(0.22 ; 2.2$ or $22 \mu \mathrm{g} / \mathrm{ml})$ of 0797 for $144 \mathrm{~h}$. At 24,72 and after $144 \mathrm{~h}$ pictures were taken and the cells were counted. The pictures of $22 \mu \mathrm{g} / \mathrm{ml}$ Q797 shown are representative of two independent experiments (A). The total cell number of triplicate wells was quantified (B). Similar results were obtained in two independent experiments. Values are mean \pm SD from 3 cultures in 2 independent experiments.

inhibited the proliferation of HUVEC $(P<0.01)$ (Fig. 4C). The inhibitory effect exerted by Q797 was reversible as shown by the ability of HUVEC to recover their proliferative capacity after $6 \mathrm{~h}$ of incubation with the compound followed by an extensive washing and incubation with fresh medium. This confirms that Q797 has a cytostatic effect in the absence of cytotoxicity. Interestingly, Q797 did not exert any cytostatic effect on the human tumor cell lines HeLa, A549, and MCF7 when tested under the same experimental conditions (Fig. 4D).

In addition, $22 \mu \mathrm{g} / \mathrm{ml}$ Q797 also prevented the ability of HUVEC to form cord-like structures when seeded on Matrigel (Fig. 4E). This inhibition was not observed when lower concentrations of Q797 were used.

\subsection{Effect of $\mathrm{Q} 797$ on endothelial intracellular signaling}

Angiogenesis requires the coordinated activation of various signaling pathways, including the phosphatidylinositol 3-kinase (PI3K)/Akt and the ERK signaling pathways (Jiang and Liu, 2008; Kuida and Boucher, 2004). As shown in Fig. 5, Q797 inhibited both bFGF- and VEGF-induced Akt and ERK phosphorylation in HUVEC when tested at the concentration of $22 \mu \mathrm{g} / \mathrm{ml}(P<0.001)$. In contrast, we did not observe any effect of this chalcone on nuclear translocation of the p65 subunit of NF- $\kappa B$ when HUVEC 

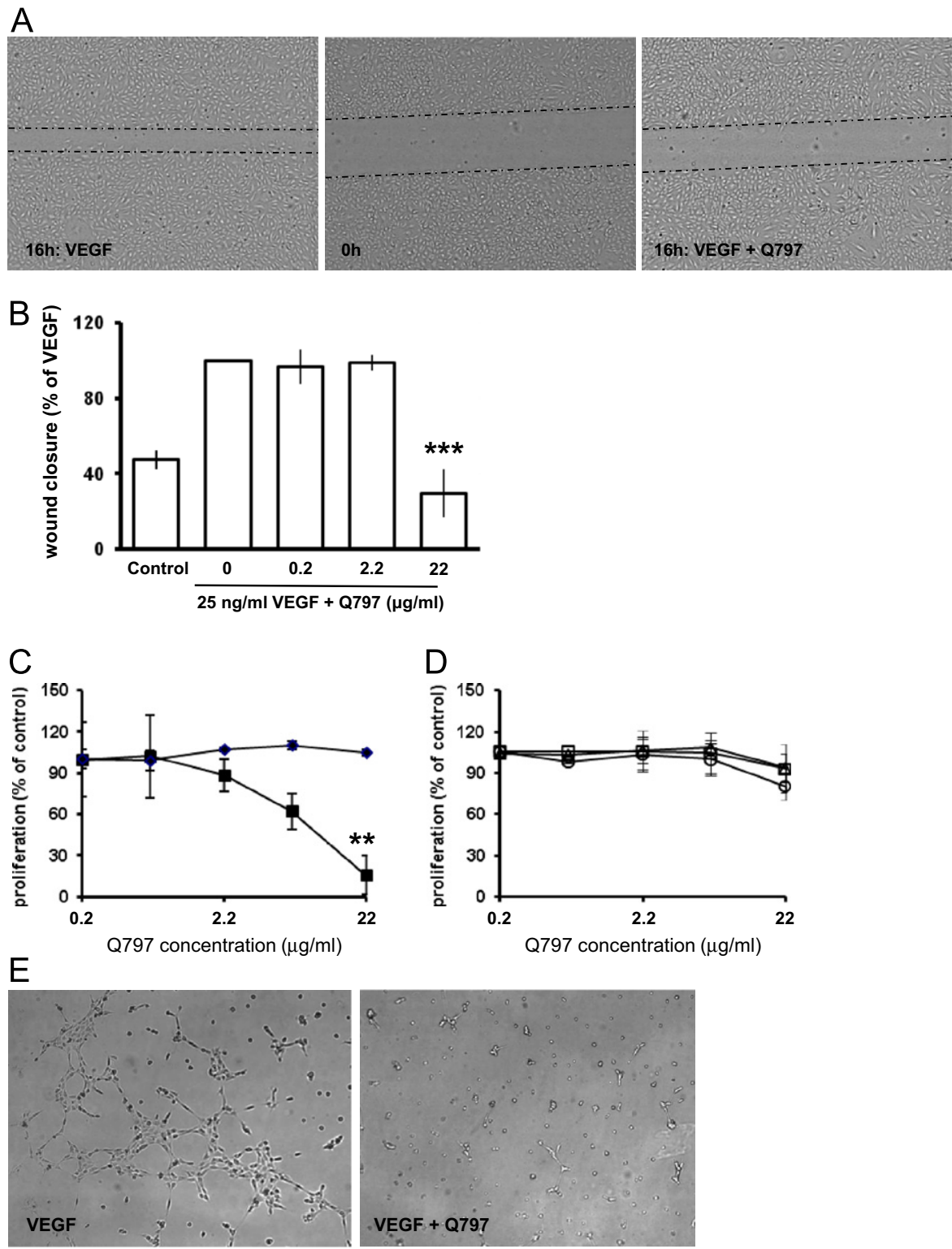

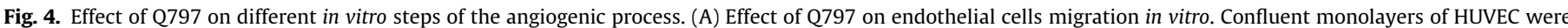

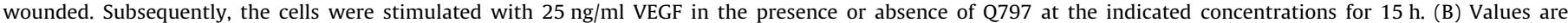

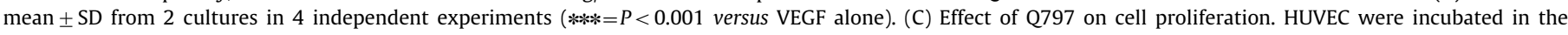

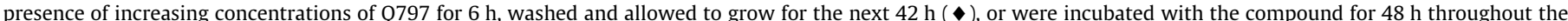

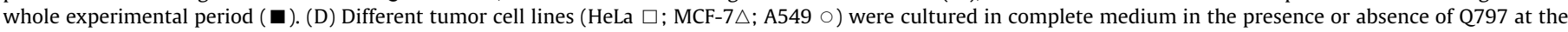

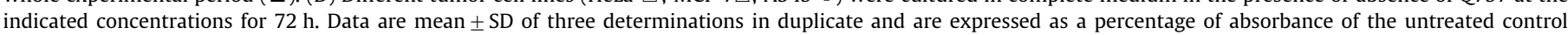

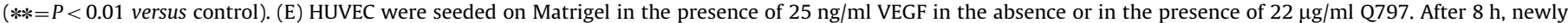
formed endothelial cell tubular structures were photographed. The pictures shown are representative of two independent experiments.

were stimulated with TNF- $\alpha$ (Fig. 6), thus confirming the specificity of the effect of Q797 on angiogenic growth factor-mediated signaling.

\subsection{Q797 inhibits angiogenesis in vivo}

Q797 was assessed for its anti-angiogenic activity in vivo on the chick embryo CAM. To this purpose, $5 \mu$ l alginate beads containing $150 \mathrm{ng}$ of bFGF in the absence or in the presence of $5.6 \mu \mathrm{g} / \mathrm{ml}$ of chalcone Q797 were applied topically on the CAM at day 10 of development. As is shown in Fig. 7, bFGF-pellets trigger a potent angiogenic response that was significantly inhibited by Q797 $(P<0.05)$. Interestingly, Q797 does not exert any effect on the basal vascularisation of the CAM and does not affect the development and survival of the chick embryos (data not shown).

\section{Discussion}

In the present study, we demonstrated the in vitro and in vivo anti-angiogenic activity of the flavonoid precursor 4-hydroxychalcone (Q797). Q797 was one of the 10 compounds that were tested using the in vitro angiogenesis model in which human microvascular endothelial cells cultured on fibrin matrices form capillary-like tubular structures when stimulated with the combination of either VEGF or bFGF and TNF- $\alpha$ (Koolwijk et al., 1996). Q797 showed potential anti-angiogenic properties on the formation of tube-like structures of endothelial cells in 3D fibrin matrices, on the 2D migration of endothelial cells, and on HUVEC proliferation. This anti-angiogenic capacity of Q797 seemed to be selective towards activated endothelial cells and not towards quiescent HUVEC monolayers or the human tumor cell lines 


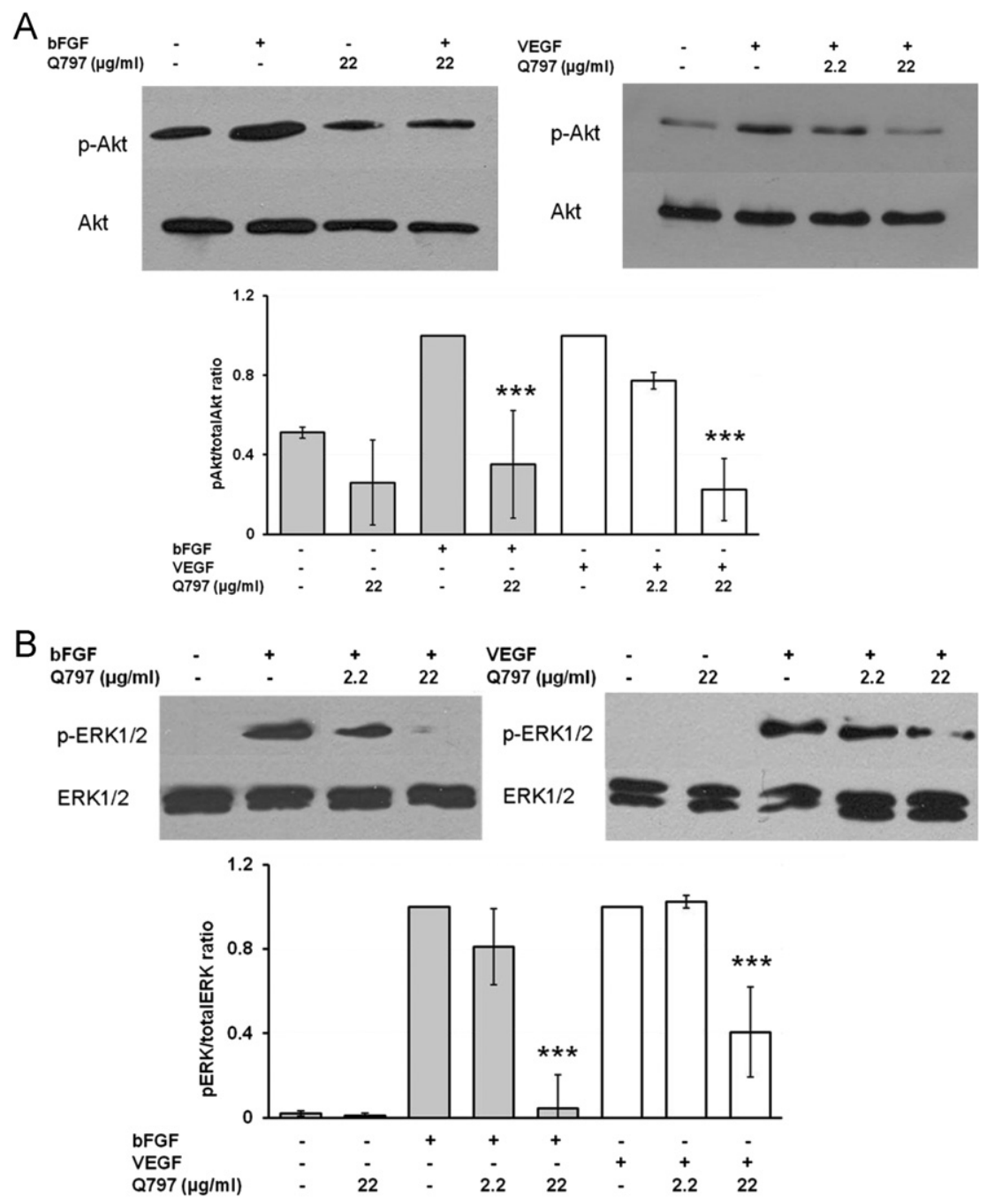

Fig. 5. Q797 inhibits VEGF- and bFGF-induced ERK1/2 and Akt phosphorylation in HUVEC. HUVEC cultured in M199 supplemented with $10 \%$ HS and $10 \%$ NBCS were pretreated with the indicated concentrations of Q797 for $1 \mathrm{~h}$ and then stimulated with $25 \mathrm{ng} / \mathrm{ml}$ of VEGF or $10 \mathrm{ng} / \mathrm{ml} \mathrm{of} \mathrm{bFGF} \mathrm{for} 15$ min before collection. Phosphorylated and total Akt (A) or ERK1/2 (B) were detected by specific antibodies. The pictures shown are representative of three independent experiments. Western blots were quantified by densitometry and ratio of phosphorylated ERK or phosphorylated Akt to their total counterpart was expressed as mean \pm SD of three experiments. $(* * *=P<0.001)$.
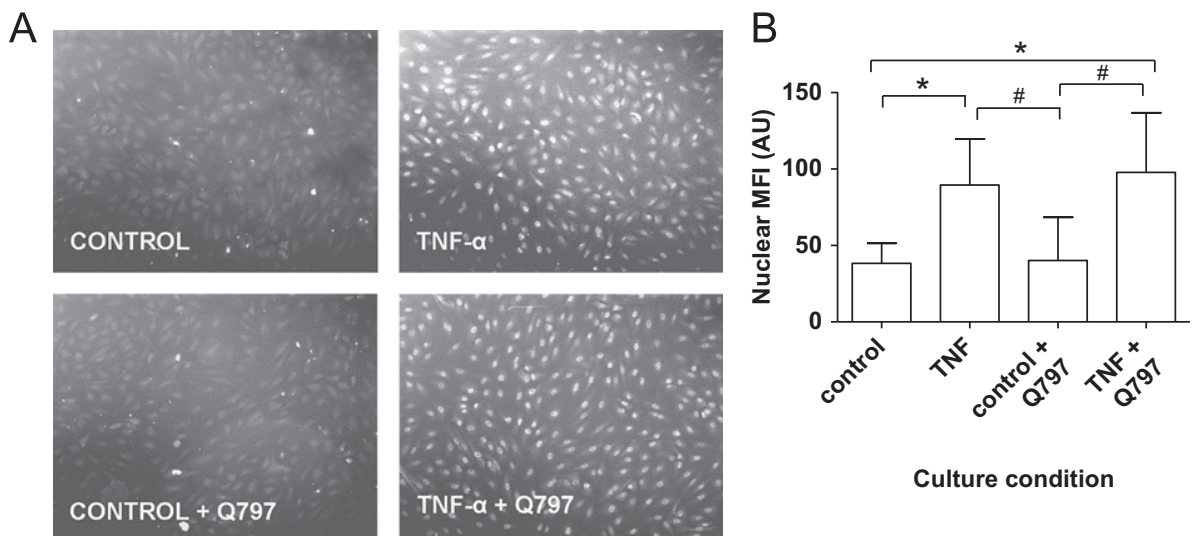

Culture condition

Fig. 6. Lack of effect of Q797 on TNF $\alpha$-induced NF- $\kappa B$ translocation in HUVEC. HUVEC were pretreated with or without $22 \mu \mathrm{g} / \mathrm{ml}$ of $\mathrm{Q} 797 \mathrm{for} 1 \mathrm{~h}$ in M199 supplemented with $10 \% \mathrm{HS}$ and $10 \%$ NBCS. Then, cells were washed and incubated with either control medium (control and control + Q797) or $10 \mathrm{ng} / \mathrm{ml}$ TNF- $\alpha$ (TNF- $\alpha$ and TNF- $\alpha+\mathrm{Q} 797$ ) with or without Q797. After $1 \mathrm{~h}$ of incubation, HUVEC were fixed and immunostained with an anti-NF-KB antibody (panel A) and the mean fluorescence intensity (MFI) of 100 nuclei was determined (panel B) using the image analysis program SlideBook ${ }^{\mathrm{TM}}$ and was expressed as mean arbitrary (fluorescent) units (AU) $\pm \mathrm{SD}$. $*=P<0.05$ to control, \# $=P<0.05$ to control + Q797.

HeLa, A549 and MCF-7. Nam et al. (2003) also reported that $2^{\prime}, 5^{\prime}$-dihydroxychalcone showed some specificity against HUVEC since the effective anti-angiogenic concentration of their compound was lower than the $\mathrm{IC}_{50}$ value obtained for tumor cell lines. However, endothelial cell specificity is not a typical feature of chalcones, since most of the chalcones studied to date for their 


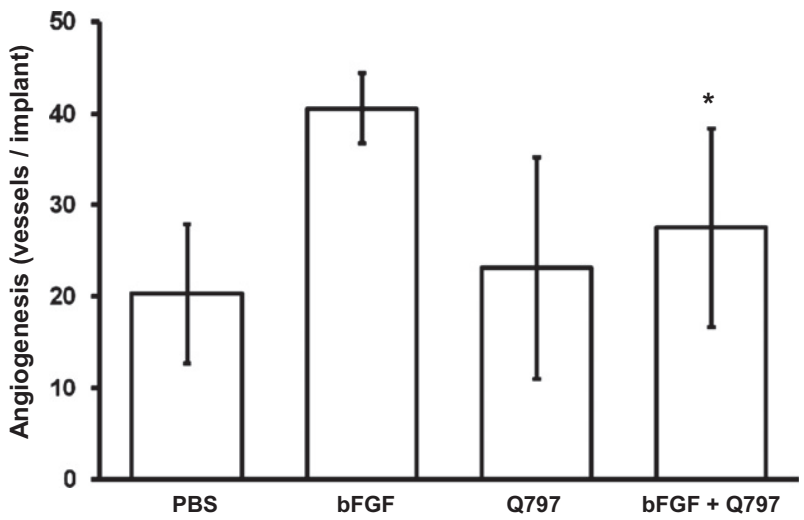

Fig. 7. Q797 impairs bFGF-induced angiogenesis. CAMs were implanted at day 10 of development with alginate beads containing vehicle (PBS), $150 \mathrm{ng}$ of bFGF, $5.6 \mu \mathrm{g} / \mathrm{ml}$ of Q797 or $150 \mathrm{ng}$ of bFGF added with $5.6 \mu \mathrm{g} / \mathrm{ml}$ of Q797. After 3 day, CAMs were photographed and angiogenesis was quantified by counting the number of microvessels (mean $\pm \mathrm{SD}$ ) invading the alginate area. Note the significant reduction by Q797 $(*=P<0.05)$ in the number of newly-formed microvessels converging towards the bFGF implant in the presence of the Q797.

anti-angiogenic potential displayed also potent antitumor activities (Albini et al., 2006; Bertl et al., 2004; Dell'Eva et al., 2007; Kim et al., 2010; Kimura and Baba, 2003; Kong et al., 2010; Lee et al., 2006; Rodrigues et al., 2011; Zhu et al., 2005). These data suggests that while other chalcones caused a non-selective effect, 4-hydroxychalcone induced a specific effect on activated endothelial cells with no cytotoxicity on quiescent cells and tumor cells.

In our study, the concentration of Q797 needed to inhibit the formation of tubular structures was high; $22 \mu \mathrm{g} / \mathrm{ml}$. However, the anti-angiogenic effect was not caused due to cytotoxicity of this chalcone. Prolonged incubation of endothelial monolayers with this concentration of Q797 did not change the morphology of the cells nor did it induce any cell death.

Zhu et al. (2005) have shown that $2^{\prime}, 4^{\prime}$-dihydroxy-6'-methoxy$3^{\prime}, 5^{\prime}$-dimethylchalcone selectively inhibited VEGF-induced endothelial cell activation via the inhibition of the phosphorylation of the vascular endothelial growth factor (VEGF) receptor 2, without having an effect on phosphorylation of the epidermal growth factor receptor. In the case of the 4-hydroxychalcone Q797 we did not find a selective inhibition of only the VEGFinduced signal pathway. We show that both bFGF as well as VEGF-stimulated in vitro tube formation and endothelial cell proliferation was inhibited. This could be explained by an interference with both VEGF as well as bFGF signal transduction cascades. This presumption was confirmed since Q797 treatment caused the repression of ERK and Akt phosphorylation in the endothelial cells not only in response to VEGF but also in response to bFGF, indicating that components of both growth factor pathways could be major targets in the molecular mechanism of Q797.

Previous studies have also shown that several chalcones could inhibit the NF- $\kappa B$ pathway (Albini et al., 2006; Madan et al., 2000; Noonan et al., 2007). NF- $\kappa B$ is considered to be a common target of anti-angiogenic drugs (Albini et al., 2007), and since TNF- $\alpha$ is used in our in vitro angiogenesis model (Koolwijk et al., 1996) we investigated whether Q797 affected the activation of the transcription factor NF- $\kappa B$ elicited by TNF- $\alpha$. In contrast to the findings of Albini et al. (2006), Madan et al. (2000) and Noonan et al. (2007), our results show that the Q797 did not suppress TNF- $\alpha$-induced nuclear translocation of the $\mathrm{p} 65$ subunit of NF- $\kappa \mathrm{B}$. These data indicate that the inhibitory effect of Q797 is not a result of inhibition of NF- $\mathrm{KB}$ pathway and that specificity of this chalcone is on growth factor-triggering angiogenesis.
To evaluate the ability of the Q797 to interfere with the angiogenic process in vivo, we used the CAM assay as a model of neo-vessel formation, and observed that Q797 significantly reduced the number of newly formed vessels in the CAM. The effect was observed in the absence of any effect on embryonic development and survival and Q797 had no harmful effect on preexisting vessels. This is in accordance with our in vitro findings. It is important to note that the use of $5.6 \mu \mathrm{g} / \mathrm{ml}$ of Q797 gave a significant inhibition effect, compared to $22 \mu \mathrm{g} / \mathrm{ml}$ in vitro.

Taken together, our study provides for the first time evidence that in vitro and in vivo administration of the flavonoid precursor 4-hydroxyhalcone caused suppression of growth factor-induced angiogenesis at a concentration that is not cytotoxic for quiescence endothelial cells. Moreover, the present study reveals that Q797mediated inhibition of in vitro angiogenesis is most likely triggered by suppression of growth factor pathways: shutting off downstream signaling cascades crucial for endothelial cell tube formation. Conversely, tumor cell proliferation was not significantly influenced even at the concentration of $22 \mu \mathrm{g} / \mathrm{ml}$ which points to an enhanced specificity of this chalcone for endothelial cells.

Further studies will reveal the more detailed mechanism of action of this compound in particular the non-concentrationdepend inhibition which we observed. There is ongoing research in our laboratory aimed at to modifying the chemical structure of Q797 in order to gain a better understanding of the relation between the chemical structure and the anti-angiogenic properties of this chalcone. Such studies could lead to development of new molecules which inhibit endothelial function in pathophysiological conditions. Our results indicate that Q797 may be a promising candidate inhibitor of angiogenesis.

\section{Acknowledgments}

This work was supported by the Slovak Research and Development Agency under the contract No. APVV-0325-07, by SEPO (ITMS code: 26220120024) and SEPO-II (ITMS code: 26220120039), by grants from Ministero dell'Istruzione, Università e Ricerca (Cofin project), Associazione Italiana per la Ricerca sul Cancro, Fondazione Berlucchi, and Fondazione Cariplo (Grant 2008-2264 and NOBEL Project), and by a grant from the Dutch Program of Tissue Engineering (DPTE 6733).

We would like to thank Dr. Sue Gibbs of the Dept. of Dermatology of the VU University Medical Center, Amsterdam, The Netherlands for careful language corrections of the manuscript.

\section{References}

Albini, A., Dell'Eva, R., Vene, R., Ferrari, N., Buhler, D.R., Noonan, D.M., Fassina, G., 2006. Mechanisms of the anti-angiogenic activity by the hop flavonoid xanthohumol: NFkappaB and Akt as targets. FASEB J. 20, 527-529.

Albini, A., Noonan, D.M., Ferrari, N., 2007. Molecular pathways for cancer angioprevention. Clin. Cancer Res. 13, 4320-4325.

Bertl, E., Becker, H., Eicher, H., Herhaus, C., Kapadia, G., Bartsch, H., Gerhäuser, C. 2004. Inhibition of endothelial cell functions by novel potential cancer chemopreventive agents. Biochem. Biophys. Res. Commun. 325, 287-295.

Chua, A.W., Hay, H.S., Rajendran, P., Shanmugam, M.K., Li, F., Bist, P., Koay, E.S., Lim L.H., Kumar, A.P., Sethi, G., 2010. Butein downregulates chemokine receptor CXCR4 expression and function through suppression of NF- $\mathrm{KB}$ activation in breast and pancreatic tumor cells. Biochem. Pharmacol. 80, 1553-1562.

de Campos-Buzzi, F., Pereira de Campos, J., Pozza Tonini, P., Corrêa, R., Augusto Yunes, R., Boeck, P., Cechinel-Filho, V., 2006. Antinociceptive effects of synthetic chalcones obtained from xanthoxyline. Arch. Pharm. (Weinheim) 339, 361-365.

Defilippi, P., van Hinsbergh, V.W.M., Bertolotto, A., Rossino, P., Silengo, L., Tarone, G., 1991. Differential distribution and modulation of expression of alpha1/beta1 integrin on human endothelial cells. J. Cell Biol. 114, 855-863.

Dell'Eva, R., Ambrosini, C., Vannini, N., Piaggio, G., Albini, A., Ferrari, N., 2007 AKT/NF-kappaB inhibitor xanthohumol targets cell growth and angiogenesis in hematologic malignancies. Cancer 110, 2007-2011. 
Dimmock, J.R., Kandepu, N.M., Nazarali, A.J., Kowalchuk, T.P., Motaganahalli, N., Quail, J.W., Mykytiuk, P.A., Audette, G.F., Prasad, L., Perjési, P., Allen, T.M. Santos, C.L., Szydlowski, J., De Clercq, E., Balzarini, J., 1999. Conformational and quantitative structure-activity relationship study of cytotoxic 2-arylidenebenzocycloalkanones. J. Med. Chem. 42, 1358-1366.

Dimmock, J.R., Vashishtha, S.C., Quail, J.W., Pugazhenthi, U., Zimpel, Z., Sudom, A.M., Allen, T.M., Kao, G.Y., Balzarini, J., De Clercq, E., 1998. 4-(beta-Arylvinyl)3-(beta-arylvinylketo)-1-ethyl-4-piperidinols and related compounds: a novel class of cytotoxic and anticancer agents. J. Med. Chem. 41, 4012-4020.

Ducki, S., 2007. The development of chalcones as promising anticancer agents. IDrugs 10, 42-46.

Folkman, J., 1995. Angiogenesis in cancer, vascular, rheumatoid and other disease. Nat. Med. 1, 27-31.

Folkman, J., 2007. Angiogenesis: an organizing principle for drug discovery? Nat. Rev. Drug Discovery 6, 273-286.

Go, M.L., Wu, X., Liu, X.L., 2005. Chalcones: an update on cytotoxic and chemoprotective properties. Curr. Med. Chem. 12, 481-499.

Grant, D.S., Tashiro, K.I., Segui-Real, B., Yamada, Y., Martin, G.R., Kleinman, H.K., 1989. Two different laminin domains mediate the differentiation of human endothelial cells into capillary-like structures in vitro. Cell 58, 933-943.

Hollman, P.C., Katan, M.B., 1999. Dietary flavonoids: intake, health effects and bioavailability. Food Chem. Toxicol. 37, 937-942.

Hsieh, H.K., Tsao, L.T., Wang, J.P., Lin, C.N., 2000. Synthesis and anti-inflammatory effect of chalcones. J. Pharm. Pharmacol. 52, 163-171.

Jiang, B.H., Liu, L.Z., 2008. AKT signaling in regulating angiogenesis. Curr. Cancer Drug Targets 8, 19-26.

Kang, S.W., Choi, J.S., Choi, Y.J., Bae, J.Y., Li, J., Kim, D.S., Kim, J.L., Shin, S.Y., Lee, Y.J Kwun, I.S., Kang, Y.H., 2010. Licorice isoliquiritigenin dampens angiogenic activity via inhibition of MAPK-responsive signaling pathways leading to induction of matrix metalloproteinases. J. Nutr. Biochem. 21, 55-65.

Kaspers, G.J., Veerman, A.J., Pieters, R., Broekema, G.J., Huismans, D.R., Kazemier K.M., Loonen, A.H., Rottier, M.A., van Zantwijk, C.H., Hählen, K., van Wering, E.R., 1994. Mononuclear cells contaminating acute lymphoblastic leukaemic samples tested for cellular drug resistance using the methyl-thiazol-tetrazolium assay. Br. J. Cancer 70, 1047-1052.

Katsori, A.M., Hadjipavlou-Litina, D., 2009. Chalcones in cancer: understanding their role in terms of QSAR. Curr. Med. Chem. 16, 1062-1081.

Kim, Y.H., Shin, E.K., Kim, D.H., Lee, H.H., Park, J.H., Kim, J.K., 2010. Anti-angiogenic effect of licochalcone A. Biochem. Pharmacol. 80, 1152-1159.

Kimura, Y., Baba, K., 2003. Antitumor and antimetastatic activities of angelica keiskei roots, part 1: isolation of an active substance, xanthoangelol. Int. J. Cancer 106, 429-437.

Knoll, A., Schmidt, S., Chapman, M., Wiley, D., Bulgrin, J., Blank, J., Kirchner, L. 1999. A comparison of two controlled-release delivery systems for the delivery of amiloride to control angiogenesis. Microvasc. Res. 58, 1-9.

Kong, Y., Wang, K., Edler, M.C., Hamel, E., Mooberry, S.L., Paige, M.A., Brown, M.L., 2010. A boronic acid chalcone analog of combretastatin A-4 as a potent antiproliferation agent. Bioorg. Med. Chem. 18, 971-977.

Koolwijk, P., van Erck, M.G., de Vree, W.J., Vermeer, M.A., Weich, H.A., Hanemaaijer, R., van Hinsbergh, V.W., 1996. Cooperative effect of TNFalpha, bFGF, and VEGF on the tube formation of tubular structures of human microvascular endothelial cells in a fibrin matrix. Role of urokinase activity. J. Cell Biol. 132, 1177-1188.

Kuida, K., Boucher, D.M., 2004. Functions of MAP kinases: insights from genetargeting studies. J. Biochem. 135, 653-656.

Lamoral-Theys, D., Pottier, L., Dufrasne, F., Nève, J., Dubois, J., Kornienko, A., Kiss, R., Ingrassia, L., 2010. Natural polyphenols that display anticancer properties through inhibition of kinase activity. Curr. Med. Chem. 17, 812-825.

Larsen, C.A., Dashwood, R.H., Bisson, W.H., 2010. Tea catechins as inhibitors of receptor tyrosine kinases: mechanistic insights and human relevance. Pharmacol. Res. 62, 457-464.
Lee, Y.S., Lim, S.S., Shin, K.H., Kim, Y.S., Ohuchi, K., Jung, S.H., 2006. Anti-angiogenic and anti-tumour activities of $2^{\prime}$-hydroxy-4'-methoxychalcone. Biol. Pharm. Bull. 29, 1028-1031

Liu, X., Go, M.L., 2006. Antiproliferative properties of piperidinylchalcones. Bioorg. Med. Chem. 14, 153-163.

Madan, B., Batra, S., Ghosh, B., 2000. 2'-Hydroxychalcone inhibits nuclear factorkappaB and blocks tumor necrosis factor-alpha and lipopolysaccharideinduced adhesion of neutrophils to human umbilical vein endothelial cells. Mol. Pharmacol. 58, 526-534.

Martínez-Poveda, B., Quesada, A.R., Medina, M.A., 2005. Hypericin in the dark inhibits key steps of angiogenesis in vitro. Eur. J. Pharmacol. 516, 97-103.

Modzelewska, A., Pettit, C., Achanta, G., Davidson, N.E., Huang, P., Khan, S.R., 2006. Anticancer activities of novel chalcone and bis-chalcone derivatives. Bioorg. Med. Chem. 14, 3491-3495.

Mojzis, J., Varinska, L., Mojzisova, G., Kostova, I., Mirossay, L., 2008. Antiangiogenic effects of flavonoids and chalcones. Pharmacol. Res. 57, 259-265.

Nam, N.H., Kim, Y., You, Y.L., Hong, D.H., Kim, H.M., Ahn, B.Z., 2003. Cytotoxic 2', 5 -dihydroxychalcones with unexpected anti-angiogenic activity. Eur. J. Med. Chem. 38, 179-187.

Nerya, O., Musa, R., Khatib, S., Tamir, S., Vaya, J., 2004. Chalcones as potent tyrosinase inhibitors: the effect of hydroxyl positions and numbers. Phytochemistry $65,1389-1395$.

Noonan, D.M., Benelli, R., Albini, A., 2007. Angiogenesis and cancer prevention: a vision. Recent Res. Cancer Res. 174, 219-224.

Perjesi, P., Nusser, T., Tarczay, G., Sohar, P., 1999. E-2-Benzylidenebenzocycloalkanones. Stereostructure and NMR spectroscopic investigation. J. Mol. Struct. 479, 13-19.

Ribatti, D., 2009. The discovery of anti-angiogenic molecules: a historical review. Curr. Pharm. Des. 15, 345-352.

Rodrigues, J., Abramjuk, C., Vásquez, L., Gamboa, N., Domínguez, J., Nitzsche, B., Höpfner, M., Georgieva, R., Bäumler, H., Stephan, C., Jung, K., Lein, M., Rabien, A., 2011. New 4-maleamic acid and 4-maleamide peptidyl chalcones as potential multitarget drugs for human prostate cancer. Pharm. Res. 28, 907-919.

Sharma, M., Chaturvedi, V., Manju, Y.K., Bhatnagar, S., Srivastava, K., Puri, S.K., Chauhan, P.M., 2009. Substituted quinolinyl chalcones and quinolinyl pyrimidines as a new class of anti-infective agents. Eur. J. Med. Chem. 44, 2081-2091.

Sivakumar, P.M., Muthu Kumar, T., Doble, M., 2009a. Antifungal activity, mechanism and QSAR studies on chalcones. Chem. Biol. Drug Des. 74, 68-79.

Sivakumar, P.M., Priya, S., Doble, M., 2009b. Synthesis, biological evaluation, mechanism of action and quantitative structure-activity relationship studies of chalcones as antibacterial agents. Chem. Biol. Drug Des. 73, 403-415.

Tomas-Barberan, F.A., Clifford, M.N., 2010. Flavones, chalcones and dihydrochalcones-nature occurrence and dietary burden. J. Sci. Food Agric. 80, 1073-1080.

van Hinsbergh, V.W., Sprengers, E.D., Kooistra, E.A., 1987. Effect of thrombin on the production of plasminogen activators and PA inhibitor- 1 by human foreskin microvascular endothelial cells. Thromb. Haemost. 57, 148-153.

Won, S.J., Liu, C.T., Tsao, L.T., Weng, J.R., Ko, H.H., Wang, J.P., Lin, C.N., 2005. Synthetic chalcones as potential anti-inflammatory and cancer chemopreventive agents. Eur. J. Med. Chem. 40, 103-112.

Yang, S.C., Wang, H., Li, G.X., Yang, Z., Guan, F., Jin, H., 2011. Cancer prevention by tea: Evidence from laboratory studies. Pharmacol. Res. 64, 113-122.

Zhu, X.F., Xie, B.F., Zhou, J.M., Feng, G.K., Liu, Z.C., Wei, X.Y., Zhang, F.X., Liu, M.F., Zeng, Y.X., 2005. Blockade of vascular endothelial growth factor receptor signal pathway and antitumor activity of ON-III $\left(2^{\prime}, 4^{\prime}\right.$-dihydroxy-6'-methoxy-3', $5^{\prime}$-dimethylchalcone), a component from Chinese herbal medicine. Mol. Pharmacol. 67, 1444-1450. 